\title{
Acesso e permanência no ensino superior: problematizando a evasão em uma nova universidade federal
}

\author{
Nadir Zago ${ }^{1}$ \\ Lea Pinheiro Paixão ${ }^{2}$ \\ Thiago Ingrassia Pereira ${ }^{3}$
}

\section{Resumo}

O trabalho se inscreve no contexto atual de expansão e de interiorização do ensino superior público brasileiro. Elegemos como eixo de análise a evasão no ensino superior, considerando sua relevância sociológica relacionada à permanência de estudantes na universidade pública. Interessamo-nos particularmente em responder às seguintes questões: os estudantes que interrompem o curso universitário revelam desistência de um determinado curso, de uma instituição ou expressam fenômenos de outra ordem? Trata-se de uma evasão do sistema ou de um "abandono" provisório? A pesquisa foi realizada na UFFS - Campus Erechim - universidade criada em 2009. Os dados foram coletados no ano de 2014 através de questionário respondido por acadêmicos desistentes, conforme registros da instituição. Os resultados evidenciaram a pertinência de se associar evasão com mobilidade, pois conceituar as situações encontradas na pesquisa como evasão, no sentido de abandono, seria mascarar a complexidade do fenômeno, em benefício de uma generalização.

Palavras-chave: Ensino superior. Expansão e interiorização. Evasão.

1 Doutorado e pós-doutorado em Educação - UNOCHAPECÓ/SC.

2 Doutorado e pós-doutorado em Educação - UFF.

3 Doutor em Educação - UFRGS. 


\title{
Access and permanence in higher education: problematizing evasion in a new federal university
}

\begin{abstract}
The present study is related to nowadays context of expansion and distribution of public universities in Brazil. We were, particularly, interested in answering the following questions: the students that give up their university studies, do so in relation to a specific course of an institution or this express a phenomenon of other sources? Does that show an evasion of the system of a provisory "abandonment"? The research was conducted at UFF - Campus of Erechim, an university created in 2009. The data was collected in 2014 using a questionnaire which was answered by students that gave up their studies, according to information provided by the institution. The results show the relevance of associating evasion with mobility as attempts to conceptualize the situations found in the research in terms of evasion, in the sense of abandonment, would rather benefit a generalization, hiding, therefore, the complexity of the phenomenon.
\end{abstract}

Keywords: University studies. Expansion. Evasion.

\section{Introdução}

Em diferentes momentos históricos, a reforma universitária apresentase como objeto de estudo que desperta tanto o interesse acadêmico quanto o da sociedade em geral. Apesar de ser uma instituição quase milenar, a universidade no Brasil é um fenômeno que não completou um século. Dessa forma, sua constituição evidencia a influência de modelos tradicionais do contexto europeu, bem como estadunidense (SGUISSARDI, 2009).

Sobretudo a partir de 2003, observamos ações e programas governamentais que passaram a atuar na criação de uma agenda de 
expansão e de interiorização do acesso ao ensino superior. Por meio de um conjunto de políticas públicas, o governo federal acenou para o crescimento do número de matrículas nos cursos de graduação e do acesso a segmentos sociais historicamente excluídos desse nível de ensino.

O Exame Nacional do Ensino Médio (ENEM) nos processos seletivos e como pré-requisito para a política de bolsas, a adoção de ações afirmativas, como as políticas de cotas sociais e étnicas, bem como a reorganização do financiamento estudantil e a aposta na criação de vagas públicas, seja pelo Prouni, em instituições privadas, seja em novas instituições públicas, são movimentos que instituíram novos arranjos no ensino superior.

Diante desse cenário, abre-se um campo de análise que permite o acompanhamento desse processo, explorando seus limites e potencialidades. Se houve progressos na ampliação do acesso ao ensino superior, a permanência dos alunos nesse nível de ensino é ainda problemática, e um de seus indícios é o fenômeno da evasão. Portanto, ocorreram mudanças nas formas de exclusão, pois, se antes ela se dava prioritariamente pela contenção no acesso, hoje, a exclusão se faz no interior do sistema de ensino.

Este estudo pretende contribuir com o debate sobre evasão no ensino superior considerando a relevância de tal fenômeno como um indicador de problemas relativos à permanência de estudantes na universidade pública. Ele se inscreve, então, no âmbito de discussões mais amplas sobre desigualdades na educação no Brasil. Nesse sentido, interessa-nos investigar questões relacionadas ao acesso e à permanência de estudantes nesse contexto de expansão das oportunidades de acesso ao ensino superior, como descreveremos na continuidade deste texto.

\section{Expansão e interiorização do ensino superior: dimensões contextuais}

Proceder no esforço de compreensão acerca das possibilidades e dos limites do atual cenário do ensino superior brasileiro é uma tarefa 
importante e que tem encontrado espaço na agenda de pesquisadores das ciências sociais e da educação. Segundo Lampert (2010), "no século XXI, esse é um tema desafiador que merece uma análise acurada do governo, da sociedade civil organizada e, principalmente, da academia" (LAMPERT, 2010, p. 19).

No Brasil, o ensino superior esteve, desde a sua origem, reservado para uma pequena parcela da população; entre outros fatores, pela sua formação tardia; se comparado a outros países latino-americanos, e pelo alto grau de seletividade em seu acesso. Nos anos 1990, a expansão de vagas ocorreu sobretudo no setor privado, e foi concentrada nas áreas metropolitanas (NEVES; RAIZER; FACHINETTO, 2007). Essa forma de expansão do ensino superior brasileiro ocorreu via capital internacional privado, articulado com o capital nacional, fomentando a oligopolização do sistema (fusão de grupos empresariais que criam grandes redes).

O cenário dos anos 1990 é de retração do ensino superior público, pautado em políticas neoliberais. Ao considerar o ensino privado, estamos nos referindo à sua essência mercantil; por seu intermédio, a educação como bem público e direito social passa a ser tratada como mercadoria. Essa lógica mercantil, mesmo que mais evidente em instituições privadas, penetra na própria administração do Estado, criando o que alguns autores chamam de "quase mercado" (PERONI, 2007).

Contudo, é importante não criarmos uma falsa ideia de homogeneidade no setor privado. A construção histórica do ensino superior brasileiro revela que, entre as instituições pagas, há o segmento comunitárias, instituições sem fins lucrativos que se inserem numa lógica "pública não estatal" (MACHADO, 2009).

Pela configuração política e econômica dos últimos anos, principalmente a partir da LDB/1996, as instituições não estatais convergem para práticas mercantis, seja pela preponderância da lógica de mercado na atuação das instituições, seja pelas dificuldades das instituições comunitárias encontrarem seu espaço de atuação (BECHI, 2011) na fronteira entre o público e o privado.

A partir de 2003, políticas públicas foram postas em prática visando 
à expansão e à interiorização ${ }^{4}$ do acesso ao ensino superior brasileiro. Tais medidas surgem a partir de políticas neodesenvolvimentistas em que o Estado passa a ter papel indutor em processos de criação de vagas públicas. A partir desse período, destacam-se diversas políticas públicas de expansão do acesso ao ensino superior: (1) 2004: Programa Universidade para Todos (Prouni); (2) 2005: Universidade Aberta do Brasil (UAB); (3) 2007: Programa de Apoio a Planos de Reestruturação e Expansão das Universidades Federais (REUNI); (4) Fundo de Financiamento ao Estudante do Ensino Superior (FIES).

As políticas adotadas instauram uma situação complexa, na medida em que procuram enfrentar o problema das desigualdades de acesso ao ensino superior voltando-se tanto para o setor público quanto para o privado. Na esfera pública, há a expansão da rede de ensino superior, o que visa à massificação do sistema. A expansão de universidades federais, via REUNI, acontece de forma concomitante ao Prouni, programa este que gerou muitas críticas, na medida em que beneficia, pela compra de vagas, as instituições privadas. Retomando dados citados por Leher (2010):

No período 1995-2006, o número de estudantes de graduação cresceu $65 \%$, os de mestrado $170 \%$ e os de doutorado $280 \%$, enquanto o número de professores aumentou somente $20 \%$. Como as metas do Reuni foram estabelecidas a partir dessa expansão anterior, não surpreende, pois, que, com o Reuni, o custo aluno deverá ser reduzido de $\mathrm{R} \$ 9,7$ mil (conforme estudo do Tribunal de Contas da União) para R 5 mil, redução na ordem de $50 \%$, que, na Europa, aconteceu em duas décadas e se deu a partir de um per capita muito maior e em instituições com infraestrutura consideravelmente superior, mas que, ainda assim, deflagrou importantes lutas estudantis e de professores em diversos países (LEHER, 2010, p. 398).

O REUNI parte de indicadores como: o descompasso entre oferta e procura do ensino superior brasileiro, o caráter majoritariamente privado do sistema e, como desdobramento, a necessidade de o Estado investir

4 Refere-se ao processo de fomento à criação de novas instituições fora das áreas metropolitanas do país, dinamizando relações culturais e econômicas. 
em cursos noturnos e na interiorização de instituições públicas federais. Contudo, para atingir seus objetivos, o REUNI fixa metas pautadas em indicadores quantitativos (como o número de matrículas e a relação professor/aluno), e, a partir destes, condiciona a liberação de recursos financeiros às universidades.

Nesse descompasso entre a expansão do sistema e o financiamento para subsidiar as instituições de ensino superior, o processo de expansão em curso ampliou, de forma expressiva, o contingente de estudantes universitários no Brasil, em especial, de segmentos sociais historicamente excluídos desse nível de ensino. Dados do Censo de Educação Superior 2013 (BRASIL, 2014) indicam um crescimento nas taxas brutas e líquidas, assim como no total de matrículas, que chega a 7.305.977. Mesmo diante do aumento do número de instituições públicas na última década, as de caráter privado continuam majoritárias, totalizando cerca de $74 \%$ das matrículas nos cursos de graduação.

É nesse cenário de democratização inconclusa que novas instituições de ensino superior foram criadas no Brasil. Na seção seguinte, deternos-emos na interiorização do ensino superior, em particular sobre a Universidade Federal da Fronteira Sul (UFFS) e um de seus Campi, selecionado como local de pesquisa.

\section{$3 \mathrm{O}$ acesso de estudantes a uma nova universidade pública no sul do Brasil}

O debate acerca do acesso à universidade pública é uma bandeira permanente de vários movimentos populares e sindicais. Lutando contra o sucateamento das universidades públicas existentes e pela adoção de mecanismos de ações afirmativas, movimentos organizados passam a fazer pressão pela reversão dos efeitos das políticas neoliberais dos anos 1990. É nesse cenário que podemos compreender a criação de várias universidades, entre elas, a UFFS e seus Campi.

No final do século XX, o Rio Grande do Sul ainda não contava com uma universidade estadual, e as federais estavam localizadas em poucos municípios (Porto Alegre, Santa Maria, Pelotas e Rio Grande), concentrados no centro-sul do estado, onde também havia um projeto 
de criação da Universidade Federal do Pampa. Por outro lado, o norte gaúcho continuava a presenciar a omissão do Estado brasileiro (esfera federal) no tocante ao ensino superior público.

Depois de frustradas algumas tentativas de movimentos sindicais, partidários e populares em defesa de uma universidade federal para atender regiões não beneficiadas pelo ensino superior público, e tendo em vista o cenário de expansão presente na agenda política do Governo Lula, a partir de 2005, começou a ganhar corpo o Movimento PróUniversidade, que reivindicava não apenas a expansão do acesso ao ensino superior, mas também a instalação de uma universidade federal que estivesse em sintonia com as demandas regionais. Além do Rio Grande do Sul, esse projeto reunia as regiões do oeste de Santa Catarina e do sudoeste do Paraná, com dimensões sociais, culturais e econômicas semelhantes. Como observa Benincá (2011), o projeto se fortaleceu, e da "confluência de intenções, emergiu a posição de uma universidade multicampi e interestadual, o que motivou tratativas com o governo federal" (BENINCÁ, 2011, p. 42).

Depois de um período de intensas negociações, foi criada, em 11 de fevereiro de 2009, pelo MEC, a comissão de implantação da Universidade Federal da Fronteira Sul, sob a tutoria da Universidade Federal de Santa Catarina (UFSC), posteriormente regulamentada pela Lei n. 12.029, de 15 de setembro de 2009. A UFFS é oriunda do processo de expansão e de interiorização do ensino superior público brasileiro, no quadro do REUNI. Ela integra um conjunto de dezoito novas universidades federais criadas entre os anos de 2003-2013.

A UFFS situa-se na mesorregião da Grande Fronteira do MERCOSUL, que abrange 396 municípios $^{5}$ distribuídos entre o sudoeste do Paraná, o oeste de Santa Catarina e o norte do Rio Grande do Sul. Iniciou suas atividades letivas em 2010, com Campi nos municípios de Chapecó (SC), Realeza (PR), Laranjeiras do Sul (PR), Cerro Largo (RS) e Erechim (RS). No ano de 2012, foi criado o Campus Passo Fundo/RS, para a instalação do curso de Medicina.

5 Disponível em < Http://www.integracao.gov.br/programas/programasregionais/ index.asp?area $=$ spr_mes_fronteira\#>. Acesso em: 11 jan. 2012. 
Ainda em 2009 foram concluídos os primeiros concursos públicos para provimento de cargos administrativos e docentes, e foi lançado edital do processo seletivo para ingresso nos cursos de graduação. Neste $1^{\circ}$ processo seletivo, inscreveram-se 11.212 candidatos para 2.160 vagas em 42 opções de cursos, nos cinco Campi. A média da disputa ficou em 5,19 candidatos por vaga, e o curso com maior demanda foi Engenharia Ambiental e Energias Renováveis, do Campus Chapecó, com 22,3 candidatos por vaga.

Desde seus primeiros processos seletivos, havia tensionamento em relação às universidades públicas federais brasileiras que, em sua maioria, abrigam, principalmente nos cursos de maior "prestígio", estudantes provenientes do ensino básico privado e de famílias com maiores recursos econômicos. Ristoff (2011) chama a atenção para a permanência da seletividade social nos cursos universitários do país:

Apesar da expansão dos últimos anos, o campus brasileiro é, sabidamente, bem mais rico que a sociedade e, nem de longe, a origem de seus estudantes reproduz os $89 \%$ de matrículas públicas que temos no ensino médio do país. Em alguns cursos de graduação, especialmente nos de alta demanda, $92 \%$ dos estudantes são oriundos dos $11 \%$ do ensino médio privado (RISTOFF, 2011, p. 306).

A UFFS definiu como um de seus princípios ser "popular", conforme documenta seu Projeto Pedagógico Institucional (PPI) ${ }^{6}$. Assim, adotou uma política de bonificação, "fator escola pública"7, ao aluno que cursou o ensino médio ou parte dele na rede pública. Os dados que seguem, referentes ao primeiro processo seletivo (ano 2010), revelam efeitos dessa política na composição social dos universitários ingressantes:

6 Disponível em: <http://www.uffs.edu.br/index.php?option=com_content\&view=article\&id=87 \&Itemid=825>. Acesso em: 13 mar. 2010.

7 O fator escola pública consiste em um acréscimo na nota do ENEM do candidato a partir do número de anos do ensino médio cursados na rede pública. A cada ano, a bonificação é de $10 \%$ sobre a nota do ENEM. Dessa forma, se um estudante realizou todo o ensino médio na escola pública, sua nota final será a nota do ENEM multiplicada por $30 \%$ (1.3). 
[...] 93,68\% dos estudantes da UFFS são oriundos da escola pública; $79 \%$ não cursaram pré-vestibular; $87 \%$ são oriundos de famílias com renda de até cinco salários mínimos; em sua maioria são trabalhadores assalariados e $87 \%$ representam a primeira geração da família a chegar a um curso universitário. No ano de 2011 o índice foi um pouco superior a 2010, chegando a 95,55\% de alunos oriundos de escola pública (ROTTA; VITCEL; ANDRIOLI, 2012, p. 61-62).

Em relação à origem geográfica, a maioria dos aprovados no mesmo processo seletivo era procedente de regiões nas quais os Campi foram instalados: a maior proporção, no Campus Laranjeiras do Sul, Paraná, com 97\% de estudantes do mesmo estado, principalmente de cidades vizinhas; o menor percentual foi no Campus Chapecó, Santa Catarina, com $67 \%$ dos estudantes desse estado.

O município de Erechim foi um dos locais que se habilitou para receber um Campus da UFFS. Influenciaram na indicação aspectos políticos tanto em nível de movimentos sociais e populares quanto partidários e institucionais. Sua posição de referência na região do Alto Uruguai (composta por 32 municípios), alicerçada na agricultura familiar e no setor industrial, contribuiu para se tornar uma das sedes da UFFS. Sua população, em 2012, era de 97.181 habitantes $^{8}$. Em relação ao PIB per capita (ano 2011) do município, era de R $27.911,00$. Em termos educacionais, a matrícula das quinze escolas, públicas e privadas, de ensino médio existentes no município era de 10.931 estudantes em 2012, dado que evidencia a existência de um público universitário em potencial. Dos cinco estabelecimentos privados de ensino médio, em dois deles são ofertados também cursos de nível superior'

O processo desencadeado em Erechim com a instalação de uma universidade pública federal pode indicar alguns fenômenos importantes para a compreensão desse contexto expansionista. Neste trabalho, nosso interesse se volta para a permanência de estudantes no ensino superior e o problema da evasão na graduação.

8 Disponível em:<Http://www.fee.rs.gov.br/sitefee/pt/content/resumo/pg_municipios_detalhe. php?municipio=erechim>. Acesso em: 3 mar. 2014.

9 Universidade Regional Integrada do Alto Uruguai e das Missões (URI) e Faculdade Anglicana de Erechim (FAE). 


\section{Questões de pesquisa e seu processo}

Um dado que chama a atenção quando analisamos as estatísticas do ensino superior no Brasil, tanto em nível nacional quanto se considerando as instituições isoladamente, é o grande número de egressos que anualmente ficam incluídos na categoria chamada evasão do ensino. Esse fenômeno atinge diferentes cursos e instituições, sejam elas públicas ou privadas. Pesquisa citada por Baggi e Lopes (2011) "revela que, no período compreendido entre 2000 e 2005, no conjunto formado por todas as Instituições de Ensino Superior (IES) do Brasil, a evasão média foi de $22 \%$ e atingiu $12 \%$ nas públicas e $26 \%$ nas particulares" (SILVA FILHO, 2007, apud BAGGI; LOPES, 2011, p. 356).

O que nos motivou à realização de um estudo sobre o problema da evasão no ensino superior não foi o ineditismo do tema, mas a existência de uma lacuna de pesquisas voltadas para as novas instituições implantadas no país na última década e em processo de consolidação. Essa é a razão da escolha do local da pesquisa empírica, ou seja, uma universidade pública (UFFS - Campus Erechim), que iniciou seu funcionamento em 2009, em uma região que dependia fundamentalmente do setor privado.

O corpo discente da UFFS em seus Campi é composto por estudantes majoritariamente egressos do ensino médio da rede pública e originários de regiões nas quais os Campi foram instalados. Apesar desses indicadores favoráveis ao processo de democratização da educação no país, subsistem grandes desigualdades educacionais, tanto de acesso quanto de permanência no ensino superior.

Na instituição UFFS Campus Erechim, no período de 29 de março de 2010 até 04 de novembro de 2014, estavam matriculados 2.546 acadêmicos. Nesse período, foram contabilizadas 806 matrículas canceladas, 204 desistências e 77 matrículas eliminadas ${ }^{10}$, distribuídas nos nove cursos oferecidos na instituição: bacharelados em Agronomia, Arquitetura e Urbanismo e Engenharia Ambiental, licenciaturas em História, Geografia, Pedagogia, Ciências Sociais e Filosofia, e interdisciplinar, em

10 Conforme definições do Sistema de Gestão Acadêmica da UFFS/Campus Erechim: (1) matrícula cancelada "quando o aluno não realiza a rematrícula ou excede o prazo de trancamento"; (2) desistência "quando o aluno assina o Termo de Desistência"; (4) matrícula eliminada "quando o aluno não frequenta os cinco primeiros dias de aula". 
Educação do Campo.

$\mathrm{Na}$ literatura que trata do acesso ao ensino superior no Brasil, são recorrentes as críticas sobre os limites da sua expansão quantitativa sem correspondente na qualidade e na permanência do jovem no sistema de ensino. A partir dessas contradições é que se insere nossa pesquisa, voltada para as condições de permanência desse novo público que ingressa em universidades beneficiadas pelas políticas de interiorização do ensino superior público. Neste trabalho, interessamo-nos particularmente em responder as seguintes questões: (1) os estudantes que interrompem o curso universitário revelam desistência de um determinado curso, de uma instituição ou expressam fenômenos de outra ordem? (2) Trata-se de uma evasão do sistema ou de um "abandono" provisório?

Para responder essas questões realizamos, no segundo semestre de 2014, um estudo de caráter exploratório que teve como local a UFFS Campus Erechim. Nossa intenção foi a de conhecer melhor a realidade investigada para ampliar o foco de análise em direção a estudos qualitativos que possibilitassem o aprofundamento da compreensão dos processos relacionados à permanência no ensino superior e à interrupção ou ao redimensionamento dos estudos.

Com essas considerações, justificamos nossa escolha metodológica, apoiada também nas considerações de Triviños (1992): “os estudos exploratórios permitem ao investigador aumentar sua experiência em torno de determinado problema". O autor indica algumas situações de pesquisas que demandam um estudo exploratório; em nossa pesquisa, sua pertinência pode ser assim sintetizada: “[...] o pesquisador planeja um estudo exploratório para encontrar os elementos necessários que lhe permitam, em contato com determinada população, obter os resultados que deseja. Um estudo exploratório, por outro lado, pode servir para levantar possíveis problemas de pesquisa" (TRIVIÑOS, 1992, p. 109). E acrescenta: "este tipo de investigação, por exemplo, não exime a revisão da literatura, as entrevistas, o emprego de questionários, etc., tudo dentro de um esquema elaborado com a severidade característica de um trabalho científico" (TRIVIÑOS, 1992, p.109-110).

Partindo dessa concepção metodológica e das questões de pesquisa, 
optamos pela realização de um estudo apoiado em um questionário remetido aos estudantes de diversos cursos de graduação que, nos registros da instituição, estavam incluídos na lista de desistentes. O questionário foi enviado, por e-mail, para 204 pessoas dessa lista, acompanhado de uma carta com explicações sobre a pesquisa, assinada pelos três professores responsáveis. O objetivo foi obter informações desse grupo em relação aos seguintes aspectos, aqui resumidos: quem são os desistentes (especialmente: idade, sexo, local de nascimento, estado civil, cor da pele, renda média familiar, grau de escolaridade e profissão dos pais); condição do estudante no ensino superior (curso, forma de ingresso, relação estudo - trabalho, bolsa de permanência ou outra forma de auxílio, condição de permanência); razões da interrupção do curso; ocorrência de transferência de instituição ou de curso; dificuldades encontradas no curso; instituição e situação após cancelamento da matricula (inscrição em outro curso ou instituição ou outra situação).

Entre o projeto e a obtenção dos dados, há um percurso nem sempre controlado pelo pesquisador. Sobre isso, destacamos que vários e-mails retornaram, pela alteração de endereço, e a devolução de questionários foi muito aquém do número previsto de respostas, razão pela qual retomamos os contatos por e-mail e reencaminhamos o mesmo questionário reafirmando a importância da pesquisa. Nessa nova etapa, o retorno foi também pouco expressivo, mas acreditamos que foi o suficiente para um estudo exploratório, pois os dados nos forneceram pistas importantes para a problematização sobre o fenômeno da evasão e suas diferentes modalidades. Contamos com um número total de 21 questionários (aproximadamente 10\% do total) e não negligenciamos informações obtidas por e-mail, por exemplo, de estudantes que não se sentiam contemplados nos critérios da pesquisa, uma vez que estavam inscritos em outro curso ou em outra instituição.

Estamos cientes de que não podemos fazer uma generalização a partir dos dados obtidos, uma vez que eles representaram uma parcela do público registrada na instituição como desistente, não abrangendo, portanto, as matrículas canceladas e eliminadas, conforme definições anteriormente citadas. A partir da análise dos questionários, procuramos 
verificar como vem se configurando o movimento dos estudantes a partir do acesso no ensino superior, no local de estudo.

\section{A permanência na universidade e o problema da evasão: situando os estudantes da UFFS Erechim}

Estudos que vão além de indicações estatísticas para incluir a participação dos estudantes na investigação vêm demonstrando que uma categoria genérica como a evasão não dá conta das várias situações implicadas na decisão dos universitários que cancelam suas matrículas na instituição de origem. Além do problema da definição do termo, a evasão no ensino é uma questão complexa, uma vez que é mediada por diferentes fatores. Um fator importante, e provavelmente o principal, está relacionado à condição socioeconômica, mas há uma gama de outras situações de ordem pessoal, institucional, entre outras, conforme vêm indicando pesquisas sobre o assunto (BAGGI; LOPES, 2011).

Analisar resultados de pesquisa sobre o tema é um trabalho que deve começar com a compreensão sobre como a evasão foi interpretada e recebeu tratamento conceitual na pesquisa. A evasão no ensino superior pode ser analisada por curso, por instituição ou em relação ao sistema de ensino superior. Estudos podem se ocupar de uma ou de mais de uma dessas dimensões. O Ministério da Educação/MEC conceituou evasão do curso como sendo "saída definitiva do curso de origem sem conclusão, ou a diferença entre ingressantes e concluintes, após uma geração completa" (BRASIL, 1997, p. 19).

Ainda, consideramos a argumentação de Dilvo Ristoff (apud BRASIL, 1996) quando observa que há a chamada "evasão de mobilidade", a partir do processo migratório do estudante para outro curso, seja na mesma ou em outra instituição. Nesse cenário, o estudante apenas trocaria de curso ou de instituição, permanecendo no sistema.

Em estudo sobre a permanência estudantil na UFFS Erechim, Ronsoni (2014) examinou os dados sobre a evasão dos cursos e da instituição no período 2010-2012 ${ }^{11}$. A partir desse material, constatou

11 Fonte: Diretoria de Registro Acadêmico (DRA) da mesma instituição. 
que a média de evasão no Campus Erechim, nos seus três primeiros anos de funcionamento, foi de aproximadamente 37, 9\%. Os altos índices de evasão não fazem parte de um caso isolado em IES do país. Outras instituições, públicas e privadas do país, vêm igualmente realizando estudos para mapear e compreender o mesmo fenômeno em seus cursos, com altos índices de evasão ${ }^{12}$. Sem pretender fazer comparações que são perigosas quanto se trata de dados sobre evasão, dada à diversidade nas formas de cálculo, vale lembrar o estudo realizado por Vitelli (2014) sobre a evasão de estudantes que ingressaram na Unisinos, em cursos de licenciatura, no ano de 2007. Considerando o período 2007-2011, segundo o autor, foi de $65,73 \%$.

Em relação à pesquisa que realizamos, deparamo-nos com um cenário interessante para a análise sociológica, tendo em vista a história de construção da UFFS, sua intencionalidade (política e pedagógica) de instituição "popular" e, sobretudo, o perfil preponderante de estudantes oriundos da escola pública. É a partir desse cenário que buscamos entender o fenômeno da evasão na nova instituição, considerando que:

A apresentação de índices sobre evasão deve ser entendida tão somente como passo inicial de análises que devem buscar identificar e compreender os fatores que a ocasionam. Tais fatores podem ser de caráter interno às instituições, específicos à estrutura e dinâmica de cada curso - ou externos a elas, relacionados a variáveis econômicas, sociais, culturais, ou mesmo individuais que interferem na vida universitária dos estudantes. Estes fatores podem ser classificados como os que se relacionam ao próprio estudante, os relacionados ao curso e à instituição e, finalmente, os fatores socioculturais e econômicos externos. Não é possível analisá-los de forma dissociada, pois fatores de uma ordem interferem necessariamente nos demais (RONSONI, 2014, p. 26-27).

A discussão que realizaremos a seguir apresenta alguns indicadores sobre esse atual cenário de expansão do acesso à universidade no Brasil. Na análise dos questionários, observamos que o processo de evasão por mobilidade (RISTOFF, apud BRASIL, 1996) encontrou apoio em

12 Ver a esse respeito: UNIPAMPA, relatório final de projeto de pesquisa, 2011. 
nossa pesquisa, uma vez que, dos 21, 15 entrevistados declararam que continuavam estudando (dois, em outro curso da mesma instituição, e 13, em outra universidade). Apenas seis informaram não continuarem no ensino superior, mas que pretendiam retomar os estudos.

De acordo com o universo pesquisado e considerando a lista de desistentes que constava na instituição no período de 2010-2014, não é possível generalizar que se tratam de saídas do sistema universitário. Os dados apresentados indicam a predominância de casos de mobilidade e, talvez, um abandono provisório e conjuntural.

Quanto ao perfil dos estudantes, a maior parte (14 dos 21) declarou ser solteiro, o que dialoga com a faixa etária expressa pelo ano de nascimento (12, ou mais da metade, nasceram a partir de 1991). Declararam não ter filhos - 18 respondentes. Na sua totalidade, são originários da área de abrangência da universidade, principalmente de cidades do Rio Grande do Sul e de Santa Catarina. Talvez isto explique a preponderância de brancos no perfil do alunado da UFFS, tendo em vista que a região sul do Brasil é constituída por processos de imigração europeia. Por outro lado, há sub-representação do segmento negro e indígena, fato que desafia a UFFS em seu projeto "popular".

O grau de instrução dos pais é indicativo do processo de mobilidade escolar geracional. Número expressivo (12 pais e 9 mães, do total de 21) não completou o ensino fundamental, e os demais continuaram os estudos, mas nem todos concluíram a educação básica. Há indicação de quatro casos extremos: uma mãe analfabeta e três mães que cursaram pós-graduação. Portanto, a maioria faz parte da primeira geração da família que teve acesso ao ensino superior, em especial, pelo processo histórico da região, em uma universidade pública federal.

Quanto à ocupação dos pais, predominam atividades ligadas à agricultura e à prestação de serviços. Em relação aos pais: seis são agricultores; sete atuam na prestação de serviços (mecânico, pedreiro, chapeador); quatro, em outras ocupações (funcionário público, empresário, representante comercial); e quatro não informaram. Em relação às mães, oito são donas de casa (três associam essa atividade com a agrícola); três são empresárias; duas atuam no ramo do ensino; as 
demais possuem outras ocupações (doméstica, costureira, cabeleireira, auxiliar de administração, auxiliar de produção, gerente de vendas).

A faixa de rendimentos demonstra o perfil de estratos populares e médios indo ao encontro dos setores ocupacionais indicados (agricultura, comércio e serviços). Trata-se de um quadro social característico da região, com predomínio de pequenos agricultores no campo, ou trabalhadores urbanos. No ensino superior, o estudo associado ao trabalho é a realidade da maioria dos respondentes, apenas sete (um terço) declararam que somente estudavam.

A escola pública é a origem de mais de $90 \%$ dos estudantes da UFFS Erechim, fato ratificado pelo grupo estudado. Do grupo de 21 que responderam o questionário, 19 cursaram todo o ensino médio na rede pública. É interessante observar que os respondentes se percebiam como bons estudantes na escola, mas declararam dificuldades em acompanhar o curso na UFFS ("aprender os conteúdos”). Para a maioria (17), o cursinho pré-vestibular não fez parte da preparação para o acesso ao ensino superior.

Um número significativo de universitários "desistentes" frequentava as primeiras fases do curso (10 interromperam no primeiro semestre), ratificando o estudo de Ronsoni (2014), que indica dados expressivos de evasão no primeiro ano letivo. Passado este momento inicial, o autor observa que a tendência é de permanência, com maior probabilidade de conclusão do curso. Nesse sentido, o melhor entendimento da rotina acadêmica e a identificação com a área de estudos são fatores importantes, quando aliados às políticas de assistência estudantil (auxílios e bolsas). Contudo, no grupo estudado, percebemos que a maioria (14, do total de 21) não teve acesso a bolsas e programas de pesquisa e extensão, bem como de ensino, como o PET e o PIBID.

Apesar de boa parte (oito, do total de 21) declarar que "sempre quis fazer o curso" que ingressou, questões como a concorrência na relação candidato e vagas oferecidas, a inexistência, na instituição, do curso pretendido, a relação do curso com o mercado de trabalho e a necessidade de frequentar ensino noturno também se destacaram como fatores condicionantes da "escolha". Uma das questões particulares do 
Campus Erechim é a oferta exclusiva de cursos de licenciatura da área das humanidades no período noturno. Há, portanto, uma "escolha tutelada", que acaba incidindo na "escolha" do estudante que trabalha, ou seja, para quem precisa trabalhar durante o dia, só encontra a opção de um curso de licenciatura no período noturno. A associação entre as duas razões assinaladas pelos questionados - "falta de identificação com o curso a que tiveram acesso" e "dificuldade de conciliar o estudo com o trabalho" - aparece de forma predominante nas justificativas da interrupção do curso, na instituição pesquisada.

Essas informações não são isoladas da falta de atratividade à carreira docente no Brasil. Assim, muitos estudantes, atraídos pelo caráter gratuito, permitem-se "testar" a entrada em um curso compatível com suas condições ${ }^{13}$, mas desistem posteriormente, por não se identificarem com a área de formação (nove, do total de 21), como atesta o depoimento de uma jovem que cursava licenciatura em História em instituição pública (UFFS) e, no momento da pesquisa, frequentava Fisioterapia, em instituição comunitária:

O tempo que passei na UFFS foi de muito aprendizado e integração na luta social. Com o tronco comum, tínhamos matérias de diversas áreas, o que me fez ir muito bem no ENEM do ano seguinte, conseguindo uma nota boa nas áreas e na redação; essa nota me fez entrar no curso de Fisioterapia pelo PROUNI, onde realmente me encontrei. No curso de História, não era tão boa aluna; embora nunca tenha reprovado em nenhuma matéria, sentia dificuldades em absorver tudo que as disciplinas nos proporcionavam. Adorava o curso, a universidade, a participação dos alunos nas decisões, mas tive que optar entre fazer Fisioterapia ou História. Hoje, tenho certeza que sou uma ótima futura-fisioterapeuta, sendo que, talvez, em História, seria apenas mais uma.

Mesmo com a ausência, no local da pesquisa, de informações sistematizadas sobre para onde migraram os estudantes, é possível identificar a ocorrência de um número considerável de transferências para instituições públicas ou privadas que garantam a permanência da

13 É revelador que oito dos 21 questionados frequentavam instituições pagas antes de ingressarem na UFFS. 
gratuidade (como pelo Prouni, no caso das particulares) e opções por outros cursos. Do total de 21 questionados, dois declararam que mudaram de curso, mas que permaneceram na UFFS (Erechim), e 14 estavam inscritos em outras instituições. Desse grupo, quatro permaneceram na rede pública (em universidades e institutos federais), e os demais, em número de 10, foram para instituições pagas (sete são acadêmicos de universidades comunitárias, e três, de faculdades particulares). Do total de 14 citados, oito frequentam instituições de ensino superior em Erechim, e seis, em outras cidades do estado.

Para ilustrar o investimento do universitário por um curso, uma instituição ou pelo turno de seu interesse, citamos algumas situações que caracterizam mobilidade para outro curso ou instituição: (1) transferência de curso na mesma instituição; (2) mudança de curso para outra instituição pública; (3) mudança de curso para instituição paga, de natureza comunitária, mas não exclusivamente.

Essas diferentes configurações de mobilidade podem ser identificadas nos depoimentos respondidos, em questionário, pelos participantes da pesquisa.

Uma estudante realizou mais do que um processo seletivo, o que lhe permitiu cancelar o curso de Engenharia Ambiental na UFFS e ingressar em outra universidade, também federal, em Engenharia Química, por considerar uma área mais próxima de seu campo de interesse. Conforme declarou: "não comecei o semestre na UFFS, pois passei em outra instituição federal, no curso que realmente queria, deste modo, cancelei minha inscrição".

Na situação que segue, a mudança não foi apenas de curso, mas também de IES e de rede de ensino público. Nos registros da universidade, a ex-estudante da UFFS consta como desistente do curso de Filosofia (frequentou um semestre); posteriormente, solicitou transferência interna e, durante três semestres, foi aluna do curso de Arquitetura. Após obter uma bolsa do Prouni, privilegiou o curso de Engenharia Civil em uma instituição comunitária, na mesma cidade, também pela possibilidade de estudar no curso noturno e de poder conciliar trabalho e estudo.

Mas há também situação inversa, como a de uma estudante que 
cursava Engenharia Civil em instituição comunitária e ingressou, em 2013, na UFFS, no curso de Ciências Sociais - licenciatura. Posteriormente, segundo informou, por não ter se identificado com o curso, a $2^{\mathrm{a}}$ chamada lhe possibilitou mudar para Arquitetura e Urbanismo, na mesma instituição.

Outro ex-estudante do curso de Arquitetura e Urbanismo na UFFS também justifica sua decisão de mudança de uma instituição pública para uma IES comunitária, forma que encontrou para cursar Engenharia Civil, conforme argumentou: "o que aconteceu foi que não consegui me identificar com as atividades desenvolvidas e me ver, futuramente, exercendo a profissão, o que agora vejo no curso que comecei desde então".

Na situação que segue, o estudante frequentava Ciências Sociais na UFFS; adotou igualmente a estratégia de mudar para uma instituição comunitária que lhe possibilitou o ingresso em Ciências Jurídicas e Sociais (Direito), curso que avalia obter melhor retorno social e financeiro, conforme seu depoimento:

O curso [Ciências Sociais] é de extrema qualidade; os professores são capacitadíssimos, do mais alto nível; com dedicação, o aluno sairá um ótimo profissional detentor do saber, entretanto, pouca oferta de concurso público, atuar somente em contratos emergenciais, sem vínculo empregatício, provavelmente será a realidade do formando. Deve-se primeiramente esperar por políticas públicas para melhorar as condições dos professores, planos de cargos e salários; é muito sacrifício pessoal e investimento em tempo para, depois de formado, ganhar apenas $\mathrm{R} \$ 1.200$ mensais.

As situações apresentadas indicam mobilidade do estudante, seja pela mudança de curso na mesma instituição, seja migrando para outras instituições, públicas ou privadas. Insatisfeitos com o curso a que tiveram acesso ou na impossibilidade de associarem trabalho com o turno do curso ofertado, tentam garantir sua permanência no sistema de ensino. Embora os casos que se enquadram nessas configurações não possam sem generalizados, em função do número reduzido de participantes na pesquisa, eles sugerem a hipótese dos efeitos, ainda que de alcance 
limitado, das políticas de interiorização do ensino superior (Reuni) e do sistema de bolsas, via Prouni, na redução das desigualdades de permanência dos estudantes no ensino superior.

Em relação aos seis ex-estudantes que não frequentavam nenhum curso no momento da pesquisa, fica a questão sobre se eles se incluem efetivamente na categoria de desistentes ou se trata-se de uma interrupção provisória, uma vez que demonstram propósitos de retomarem os estudos. As principais razões apontadas pelos questionados indicam, como já citamos, a falta de identificação com o curso, a dificuldade em conciliar o estudo com o trabalho, a falta de tempo para se dedicar aos estudos e transferência profissional. A descrição da ex-estudante de Arquitetura na UFFS ilustra a complexidade da permanência em cursos incompatíveis com a realidade social do universitário. Segundo declarou, esse era o curso que "sempre quis fazer". Sua condição de estudante e também de trabalhadora dificultou sua permanência no ensino superior. Segundo seu relato: "eu esperava poder conciliar o trabalho com o curso, mas como as aulas eram manhãs e tardes, não queria desistir do trabalho e nem do curso; gostaria que as aulas fossem no turno da noite". Ocorreram também outras dificuldades: "eu ingressei em 2010, no $1^{\circ}$ semestre, era a $1^{a}$ turma, então, faltavam professores que ministrassem as disciplinas de acordo com a sua área de formação". O cancelamento do curso não a afastou do desejo de retomar os estudos: "estou abandonando provisoriamente o ensino superior, mas pretendo voltar a cursar uma graduação".

A mudança de curso ou de instituição por parte dos universitários está com frequência associada à expectativa pragmática de investimento, em tempo e recursos, em uma formação que possibilite melhor inserção no mundo do trabalho e mudança social. Outras razões elencadas para o cancelamento do curso são de ordem pessoal (saúde, problemas financeiros, transferência do local de trabalho ou residência), falta de tempo para se dedicar aos estudos, desconhecimento prévio do curso e da carreira ou ainda relacionadas à instituição (didática dos professores e dificuldades de adaptação na universidade).

Algumas questões particularmente importantes no contexto das 
novas universidades a partir do REUNI, como as condições físicas (de estrutura) da instituição, foram mencionadas. Em relação à pergunta “o que deveria ser melhorado na UFFS?", 14 dos 21 questionados responderam "condições físicas das salas de aula e/ou laboratórios", e 10 citaram igualmente as condições físicas do refeitório e do alojamento. Isso está de acordo com o processo inicial da UFFS, em espaços alugados e provisórios, prejudicando a construção de uma "identidade" institucional nos primeiros anos.

As respostas sobre as dificuldades enfrentadas pelos estudantes, conforme uma das questões do questionário, demonstram o peso das condições materiais na permanência no ensino superior, mesmo em universidade pública. Um estudo mais aprofundado pode revelar as desigualdades acumuladas nos percursos desses estudantes, associadas à origem socioeconômica e cultural, mas, igualmente, às condições materiais de funcionamento das instituições, às questões curriculares e de ensino e aprendizagem, entre outros fatores limitadores da condição do estudante, conforme indicam também outros estudos.

\section{Considerações finais}

Não há unanimidade na forma de se registrar e de armazenar informações sobre a vida escolar dos alunos nas instituições escolares. Assim, a evasão é objeto de diferentes definições, e distintas formas de operacionalizar seus dados são encontradas.

A UFFS é parte do atual processo de expansão e de interiorização do acesso ao ensino superior levado a cabo por meio do papel indutor do Estado a partir de 2003. Nesse sentido, ao estudarmos os primeiros dados sistematizados pela nova universidade, chamamos a atenção para um fenômeno ainda pouco explorado pelo campo da Sociologia da Educação.

Certamente, se este primeiro movimento investigativo não possibilitou tecer argumentações mais substantivas sobre o processo de acesso, de permanência e de evasão da UFFS, as atividades de pesquisa realizadas em uma instituição que está ainda em fase de consolidação de seus fundamentos (ensino, pesquisa e extensão), incluindo sua estrutura 
física e de pessoal, oportunizou perceber as contradições entre o acesso e a permanência dos estudantes na universidade.

Mesmo diante de vagas públicas e gratuitas mais "perto de casa", aspectos estruturais condicionam o percurso universitário. Por isso, se, por um lado, a UFFS oferta inovação no sistema universitário federal, ao ter mais de $90 \%$ de alunos oriundos da escola pública, por outro lado, convive com o desafio da permanência de seus estudantes, tendo em vista as exigências de acompanhamento do curso, a difícil tarefa de conciliar o trabalho com o estudo e a timidez das políticas de assistência estudantil.

Em nossa pesquisa, por meio de questionários respondidos por estudantes que assinaram termo de desistência de seus cursos na UFFS Campus Erechim, é possível ratificar esse novo cenário de maiores oportunidades de ingresso na universidade, seja a partir da expansão de instituições públicas, seja por programas de bolsas em instituições privadas (Prouni).

Observamos que um número considerável de estudantes, ao desistirem de um curso na UFFS Erechim, não desistiu de estudar, migrando para outro curso da própria universidade ou para outra instituição. Por isso, não é possível associarmos diretamente o percentual de evasão à exclusão do sistema. Parece-nos pertinente associarmos o entendimento de evasão por mobilidade, pois conceituar as situações encontradas na pesquisa como evasão, no sentido de abandono do sistema, seria mascarar a complexidade do fenômeno, em benefício de uma generalização.

O conceito de evasão é definido e é utilizado por levantamentos de dados mais macro que utilizam informações do INEP, mas insuficiente quando se trata de entender de perto o que se passa em um curso ou em uma instituição. Nessa escala, torna-se imprudente fazer comparações que não sejam de caráter mais macro, e se torna necessário realizar pesquisas que focalizem tal fenômeno de mais perto. Nosso estudo exploratório aponta para essa necessidade. Trabalhamos com alunos que a instituição considera desistentes (aqueles que assinam o termo formal de desistência). Mas seria necessário buscar compreender o que se passou com aqueles que tiveram a matrícula cancelada (foram 806) e 
os que tiveram as matrículas eliminadas (foram 77).

Uma conclusão a ser retirada do presente estudo é que são precárias as possibilidades de comparação com resultados obtidos em pesquisas sobre evasão realizadas em outras instituições e até em outras unidades da mesma instituição. O que a literatura tem denominado evasão referese a situações distintas, tendo em vista ser um conceito polissêmico. Neste texto, não foi nosso objetivo proceder extensa revisão bibliográfica sobre o assunto, mas sim dialogar com algumas definições presentes na literatura de referência, inclusive em estudos nos quais a UFFS se constituiu em objeto de análise.

\section{Referências}

BECHI, D. Mercantilização do ensino superior: os desafios da universidade diante do atual cenário educacional. Acta Scientiaru Education, Maringá, v. 33, n. 1, p. 139-147, 2011.

BAGGI, C. A. S.; LOPES, D. A. Evasão e avaliação institucional no ensino superior: uma discussão bibliográfica. Avaliação, Campinas; Sorocaba, SP, v. 16, n. 2, p. 355-374, jul. 2011.

BENINCÁ, D. Uma universidade em movimento. In: BENINCÁ, D. (Org.). Universidade e suas fronteiras. São Paulo: Outras Expressões, 2011. p. 31-63.

BRASIL. Instituto Nacional de Estudos e Pesquisas Educacionais Anísio Teixeira (INEP). Coletiva Censo da Educação Superior 2013. Brasília, 2014. Disponível em: <http://download.inep.gov.br/ educacao_superior/censo_superior/apresentacao/2014/coletiva_ censo_superior_2013.pdf>. Acesso em: 22 abr. 2014.

Análise sobre a expansão das universidades federais 2003 a 2012. Brasília: Ministério da Educação, 2012. Disponível em: <http:// portal.mec.gov.br/index.php?option=com_docman\&task=doc download\&gid=12386\&Itemid=>. Acesso em: 25 set. 2014. 
ANDIFES/ABRUEM/Sesu/MEC. Diplomação, retenção e evasão em cursos de graduação em Instituições de Ensino Superior Públicas. Relatório. Comissão Especial de Estudos sobre Evasão nas Universidades Públicas Brasileiras. Brasília: Secretaria da Educação Superior, 1996.

LAMPERT, E. (Re)criar a universidade: uma premissa urgente. In: LAMPERT, E.; BAUMGARTEN, M. (Orgs.). Universidade e conhecimento: possibilidades e desafios na contemporaneidade. Porto Alegre: Sulina/Ed. UFRGS, 2010. p. 19-43.

LEHER, R. Educação no governo de Lula da Silva: a ruptura que não aconteceu. In: MAGALHÃES, J. P. A. et al. Os anos Lula: contribuições para um balanço crítico 2003-2010. Rio de Janeiro: Garamond, 2010. p. 369-412.

MACHADO, A. M. N. Universidades comunitárias: um modelo brasileiro para interiorizar a educação superior. In: SCHMIDT, J. P. (Org.). Instituições comunitárias: instituições públicas não-estatais. Santa Cruz do Sul: EDUNISC, 2009. p. 74-92.

NEVES, C. E. B.; RAIZER, L.; FACHINETTO, R. Educação superior para todos? Acesso, expansão e equidade: novos desafios para a política educacional. Sociologias, Porto Alegre, v.9, n. 17, p. 124-157, jan.-jun./2007.

PERONI, V. M. V. Reforma do estado e a tensão entre o público e o privado. Revista SIMPE-RS, Porto Alegre, ano 1, v. 1, p. 11-33, abr./2007.

RISTOFF, D. I. Construindo outra educação: tendências e desafios da educação brasileira. Florianópolis: Insular, 2011.

Universidade em foco: reflexões sobre a educação superior. Florianópolis: Insular, 1999.

RONSONI, M. L. Permanência e evasão de estudantes da UFFS Campus Erechim. In: PEREIRA, T. I. (Org.). Universidade pública em tempos de 
expansão: entre o vivido e o pensado. Erechim: Evangraf, 2014. p. 17-31.

ROTTA, E.; VITCEL, M. S.; ANDRIOLI, A. I. A Universidade Federal da Fronteira Sul e a sua experiência de inclusão por meio da instituição das cotas sociais. In: LUFT, H. M.; FALKEMBACH, E. M.; CASAES, J. B. de (Orgs.). Freire na agenda da educação: inclusão e emancipação educação de jovens e adultos. v. 2. Ijuí: Ed. Unijuí, 2012. p. 55-65.

SGUISSARDI, V. Universidade brasileira no século XXI: desafios do presente. São Paulo: Cortez, 2009.

TRIVIÑOS, A. N. S. Introdução à pesquisa em ciências sociais: a pesquisa qualitativa em educação. São Paulo: Atlas, 1987.

UNIPAMPA. A evasão na Unipampa: diagnosticando processos, acompanhando trajetórias e itinerários de formação. Relatório final: projeto de pesquisa. Bagé, RS: Universidade Federal do Pampa, 2011. $126 \mathrm{p}$.

VITELLI, R. F. Ingressantes em cursos de licenciatura: perfil do evadido e fatores intervenientes no fenômeno. In: SEMINÁRIO DE PESQUISA EM EDUCAÇÃO DA REGIÃO SUL: REUNIÃO CIENTÍFICA REGIONAL DA ANPED, Florianópolis, 2014. Anais... Disponível em: <http:/ / www. xanped.2gdev.com.br/>. Acesso em: Acesso em: 25 out. 2014.

Recebido em 08/06/2016 Aprovado em 23/06/2016 